\title{
Wastegate Actuator Modeling and Model-Based Boost Pressure Control ^
}

\author{
Andreas Thomasson* Lars Eriksson* Oskar Leufvén* \\ Per Andersson** \\ * Vehicular Systems, Dept. of Electrical Engineering \\ Linköping University, SE-581 83 Linköping, Sweden, \\ $\{$ andreast,larer,oleufven $\}$ @isy.liu.se \\ ** GM Powertrain Sweden AB, Per Andersson, SE1-A04-007 \\ SE-46180Trollhättan, per.andersson@gm.com
}

\begin{abstract}
:
The torque response of an engine is important for driver acceptance. For turbocharged spark ignited (TCSI) engines this is tightly connected to the boost pressure control, which is usually achieved with a wastegate. A challenging scenario is when the throttle is fully open and the load is essentially controlled by the wastegate. First a model for the pneumatic wastegate actuator and air control solenoid is developed. The wastegate model consists of three submodels; the actuator pressure, the static position, and an additional position dynamics. A complete engine model is constructed by including the actuator model in a Mean Value Engine Model (MVEM) for a TCSI engine. This model describes the transient boost pressure response to steps in wastegate control inputs. The subsystems and complete MVEM are validated on an engine test bench and it explains the overshoot seen in the step responses.

The model is used to study the system response and give insight into the dominating phenomena and it points out that the engine speed is important for the response. Further, for each speed it is sufficient to model the system as a second order linear system, that captures an overshoot. A controller consisting of a mapped feedforward loop and a gain scheduled feedback loop is developed together with a tuning method based on the IMC framework for the feedback loop. The controller and tuning method is shown to achieve the desired boost pressure behavior both on the complete MVEM and on real engines. The experimental validation is carried out both in an engine test cell and in a vehicle.
\end{abstract}

Keywords: Engine modeling, engine control, turbocharging, internal model control, PID.

\section{INTRODUCTION}

Turbocharging is a common way of increasing the power density of both spark ignited and diesel engines. Combining turbocharging with downsizing gives a cost effective way for improving the fuel economy of a vehicle (Emmenthal et al., 1979; Guzzella et al., 2000; Soltic, 2000; Petitjean et al., 2004). To achieve good engine performance and driveability over the full operating range it is necessary to control the turbocharger, and this is usually done with an actuator on the turbine (Watson and Janota, 1982). The most frequently used actuator is the wastegate. Boost pressure control and wastegate control has been studied in many publications, see e.g. Wakeman and Wright (1986); Kranik et al. (2005); Moulin et al. (2008); Müller (2008). A flexible wastegate system enables more advanced strategies, for example it is favorable to open the wastegate as much as possible in order to reduce pumping losses and thus fuel consumption (Eriksson et al., 2002a). For engine operating points with intake pressures above atmospheric this leads to a control strategy with fully open throttle and

* This research was supported by the VINNOVA Industry Excellence Center LINK-SIC and by the Strategic Research Center MOVIII, funded by the Swedish Foundation for Strategic Research. where the wastegate alone is used to control the boost pressure and engine torque. In general the demand for good performance combined with more advanced system configurations put higher demands on the design of boost pressure controllers.

The wastegate is normally opened by a pressure actuator connected to a pressure blender solenoid valve controlled by the ECU. The position is not measured and the static and dynamic response to control inputs depend on engine operating conditions. A complete physical model of the pressure actuator and pressure feed system is challenging since several parameters such as membrane areas, flow coefficients, valve areas and how they vary with control signal and actuator position, have to be determined. Physical modeling gives valuable insight into the system and it has been successfully applied in Moraal et al. (1999) and Galindo et al. (2009). This paper tackles the problem from another angle. A novel model for the wastegate actuator is developed, using fewer parameters that are easily tuned from measured data and that is suitable for control design evaluation. The model is divided into three submodels and captures the stationary and dynamic behavior of the system, which are needed to predict the system 


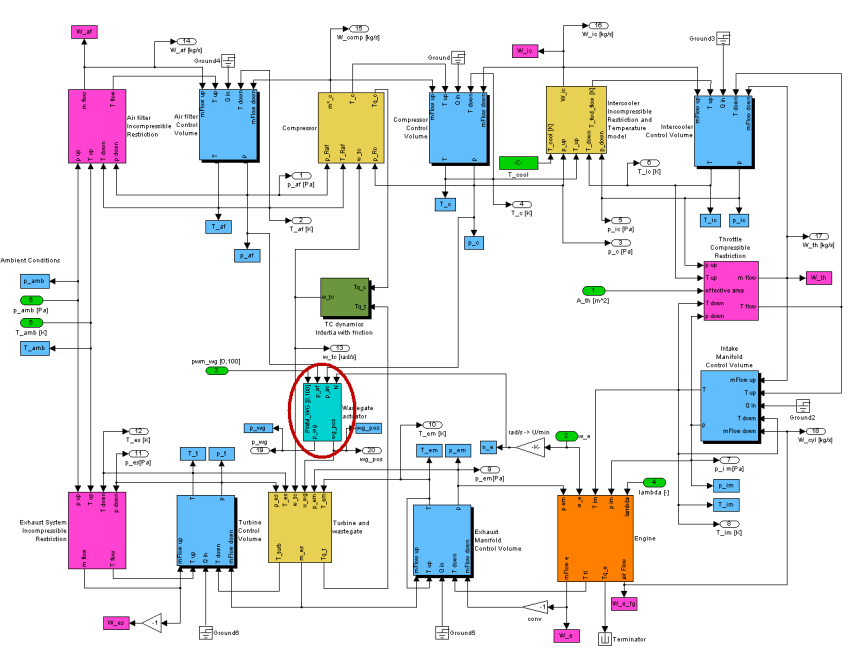

Fig. 1. The MVEM implemented in Simulink. The encircled block contains the wastegate actuator model developed in this paper.

behavior and controller performance. With the aid of a complete Mean Value Engine Model (MVEM), a modelbased tuning method for a boost controller structure is developed. The tuning method is based on linearizations of the boost pressure response to control signal. The developed wastegate actuator model is used to simulate the performance of the controller, which is then implemented and experimentally evaluated on an engine. In the development and experimental validation the emphasis is on cases where the throttle has a large opening area, i.e. where the wastegate control has a big impact on the torque response.

\subsection{Outline and experimental setup}

The development of the controller and its tuning is based on a complete MVEM of a TCSI engine, that has been developed and validated in Eriksson et al. (2002b); Andersson (2005); Eriksson (2007). This MVEM provides a gas flow model of the engine, shown in Figure 1, that is extended with the new wastegate actuator model, encircled in the figure. Section 2 describes the development of the actuator model where engine test cell data is used to build and validate this actuator model.

In Section 3 a boost pressure controller is designed. It consists of feedforward and feedback loops that fit well into the structure that is current industrial practice. The main effort is on the feedback loop. It is designed based on the IMC framework where the plant model consists of several linearizations of a reduced order MVEM for the TCSI engine. The feedforward loop is a static map that is determined in stationary experiments. It is shown that the feedback loop is not able to compensate for large errors in the feedforward during transients, hence the accuracy of the feedforward is important for performance. Controller validation is first performed on the non-linear model, in Section 4.1, and then on a vehicle, both on the road and on a vehicle dynamometer, in Section 4.2.

The wastegate model identification experiments have been performed in the engine lab of the Division of Vehicular Systems at Linköping University. The engine is a four cylinder two liter turbocharged gasoline engine with direct

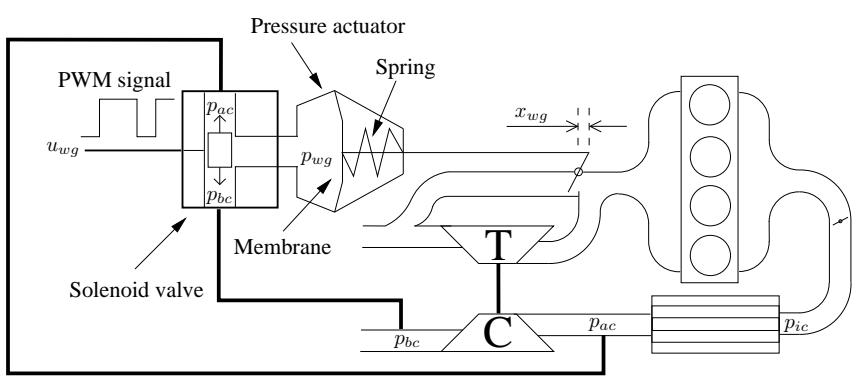

Fig. 2. A sketch of the complete system but with special emphasis on wastegate actuator and pressure blender solenoid valve.

injection. The control system from dSPACE consists of a RapidPro system and MicroAutoBox connected to a PC running Control Desk. Two extra sensors are added to the test cell setup, a linear position sensor to measure the actuator position and a pressure sensor for the pressure in the actuator. The extra sensors are used for modeling and analysis while the sensors used for control are those of a standard production engine.

The test vehicle used for controller tuning and evaluation is powered by a two liter turbocharged engine, similar to the engine in the test cell. This vehicle also uses a development control system instead of a production system.

\section{WASTEGATE ACTUATOR MODELING}

The wastegate actuator is a little studied topic in the literature but it has a significant influence on the controller performance. In particular, the transient response to changes in control signal shows an overshoot in boost pressure. This is not predicted by the MVEM without extending it with a model for the connections between the control signal and the effective area of the wastegate valve. If such a model is available then the pressure oscillations, that can be introduced by the controller, can be predicted and accounted for already in simulation, which reduces the time needed for engine calibration.

A sketch of the wastegate actuation system is shown in Figure 2. The wastegate valve is opened by a pressure actuator which is mechanically connected to the valve. The position of the actuator is denoted $x_{w g}$ and measured in percent of full opening. The pressure in the actuator $p_{w g}$ is generated by a pressure blender solenoid that is connected to the pressures before and after the compressor. The blender solenoid has as input the wastegate duty cycle $u_{w g}$, which is a pulse-width modulated signal. The wastegate actuator model has $u_{w g}$ as input and gives the wastegate position $x_{w g}$ as output and the main components are the pressure blender solenoid valve, the pressure chamber, and the actuator rod with a spring.

\subsection{Model identification experiments}

For model identification several ramp and step responses in wastegate duty cycle were made. These were done with fully open throttle and for different engine speeds. Figure 3 shows ramp responses for two different engine speeds. The ramp responses are very slow and are used to identify the static behavior of the actuator. The step responses 


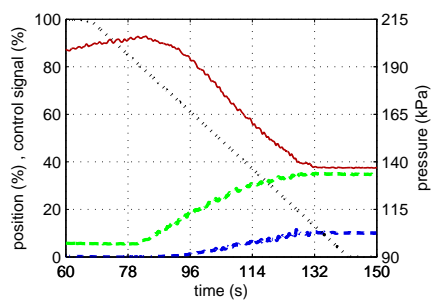

(a) $2500 \mathrm{rpm}$

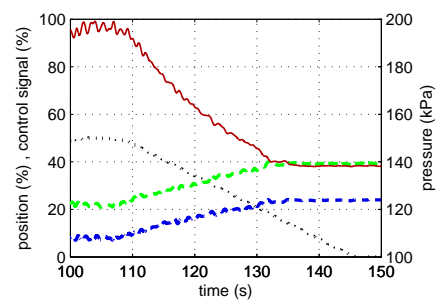

(b) 4000rpm
Fig. 3. Ramp response measured in test cell. The wastegate duty cycle $\left(u_{w g}\right.$ - black dotted) is ramped from the maximum allowed by the control system during normal operation and down to zero. As $u_{w g}$ decreases the pressure in the actuator ( $p_{w g}$ - green dashed) rises. Eventually $p_{w g}$ overcomes the spring force, the wastegate opens ( $x_{w g}$ increases - blue dash-dot) and the boost pressure decreases (red solid).

are used in section 2.6 where the actuator dynamics are treated.

\subsection{Wastegate position model - static behavior}

The wastegate actuator position is mainly affected by the pressure in the actuator. The actuator pressure generates a force in the actuator $F=p_{w g} A$, where $A$ corresponds to the actuator membrane area. This force is in its turn balanced by the spring force, described with a linear expression $F=-k_{s} x$. Assuming all other forces constant for a given speed results in the following static model

$$
\bar{x}_{w g}=k(N) \cdot\left(p_{w g}\left(u_{w g}\right)-p_{0}(N)\right)
$$

where $k$ and $p_{0}$ represent the static gain from actuator pressure to position and the opening pressure, respectively. Naturally there are other forces that also act on the wastegate, coming from the gas motion and pressure difference around the valve. To model this physically from the geometry of the valve, the surrounding pressures and gas motion is difficult. However the experiments have shown that sufficiently good accuracy can be achieved by allowing $k$ and $p_{0}$ to vary with engine speed only. However, if other applications necessitate the addition of other forces that act on the wastegate valve, they could also be fitted into the model structure.

\subsection{Wastegate position model - small openings}

It has been noted that there is a deviation between model (1) and measurements for small openings. It is believed that these deviations are due to oscillations in the wastegate position that have been observed in the measurements. In the experimental data oscillations can be seen both in the chamber pressure and in the wastegate position and they have the same frequency as the opening and closing of the intake and exhaust valves. Whether the oscillations in position are due to pressure pulsations on the intake side that propagate through the valve to the actuator chamber and to the waste gate position, or if they are caused by the pulsating flow around the valve in the exhaust, is still an open question.

Regardless of the source, if the movement follows an oscillation that is saturated then this will lead do a deviation in
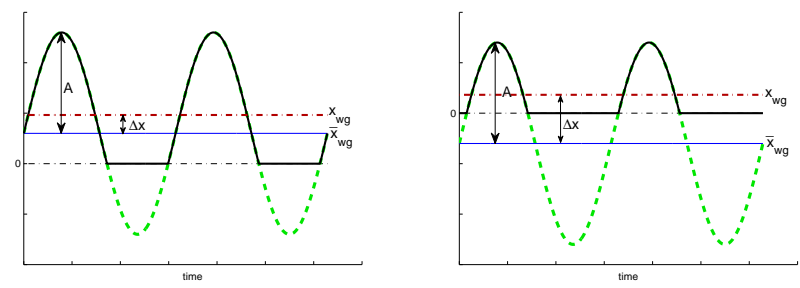

Fig. 4. Illustration of position modification for small wastegate positions. Unsaturated oscillation (green dashed) and saturated oscillation (black solid). The mean value for the saturated oscillation (red dash-dot) is larger than the mean value for the unsaturated oscillation (blue solid).

the mean value $\bar{x}_{w g}$, which is what (1) describes. Specifically, when the mean value of the oscillation is in the range of $[-A, A]$, where $A$ is the amplitude of oscillation, the mean value for the free oscillation will be lower than that of the clipped, see Figure 4 for an illustration. A simple model can be received by assuming that the oscillations follow a sinusoidal with amplitude $A$ that is saturated. The offset in mean value, $\Delta x$, due to the saturation is given by

$$
\left\{\begin{aligned}
m & =\min \left(\max \left(\bar{x}_{w g},-A\right), A\right) \\
\phi & =\cos ^{-1}(-m / A) \\
\Delta x & =\frac{1}{\pi}(A \sin (\phi)+m \phi)-m
\end{aligned}\right.
$$

where $\bar{x}_{w g}$ is given by (1) and $A$ has been chosen as the maximum amplitude of oscillation for the unfiltered signal. It is worth to note that a similar effect is expected at the maximum, where the actuator also saturates. This is not included in the model since the upper saturation is seldom reached, if it is necessary it can be modeled analogously as above. Thus the resulting model for the corrected position becomes

$$
x_{w g}=\bar{x}_{w g}+\Delta x
$$

Figure 5 compares the position model (3) to measurement data and shows that the model gives a good description of the behavior. In some cases it might not be necessary to include this sub-model, but it is simple improves the model agreement in the region near where the wastegate is closed.

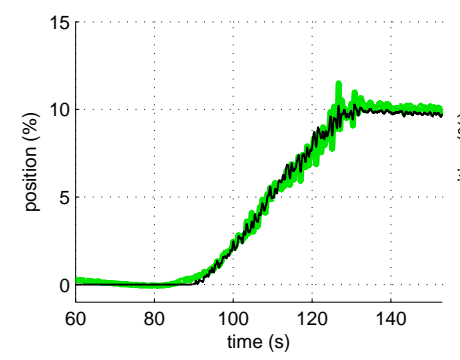

(a) $2500 \mathrm{rpm}$

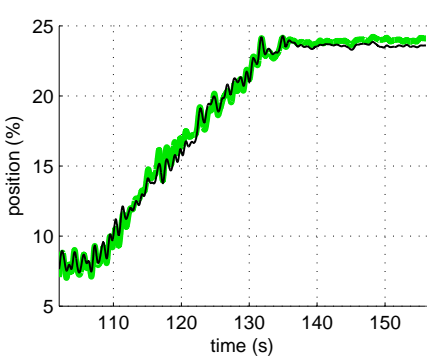

(b) $4000 \mathrm{rpm}$
Fig. 5. Comparison between the wastegate position model (black thin) and measurements (green thick) for two different engine speeds. 


\subsection{Wastegate pressure model - static behavior}

The pressure model describes the relationship between the wastegate duty cycle and the two feeding pressures to the actuator pressure. A linear interpolation between the two feeding pressures with the duty cycle as argument has proved to be insufficient. The proposed model is a second order polynomial in wastegate duty cycle, with coefficients that depend on the feeding pressures and the saturation limits of the control signal, $u_{\min }$ and $u_{\max }$. The resulting pressure model is defined by

$$
p_{w g}= \begin{cases}p_{a c} & \text { if } u_{w g}<u_{\min } \\ a u_{w g}^{2}+b u_{w g}+c & \text { if } u_{\min } \leq u_{w g} \leq u_{\max } \\ p_{b c} & \text { if } u_{w g}>u_{\max }\end{cases}
$$

The parameters $a, b, c, u_{\min }$ and $u_{\max }$ have been estimated with the least squares method under the following two algebraic constraints

- $a u_{\min }^{2}+b u_{\min }+c=p_{a c}$

- $a u_{\max }^{2}+b u_{\max }+c=p_{b c}$

that ensure that $p_{w g}$ in (4) is continuous at $u_{w g}=u_{m i n}$ and $u_{w g}=u_{\max }$. The resulting pressure model is validated in Figure 6 and it is shown that it gives a good description of the measured actuator pressure.

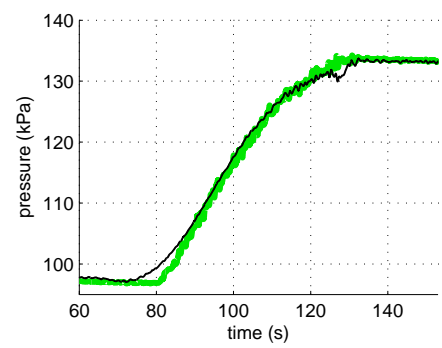

(a) $2500 \mathrm{rpm}$

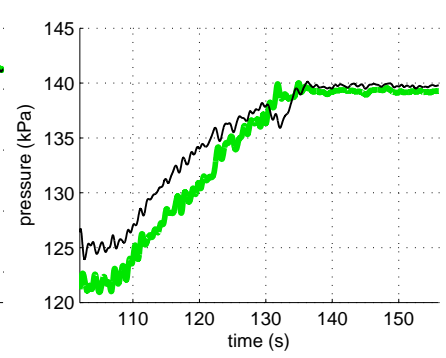

(b) 4000rpm
Fig. 6. Modeled actuator pressure (black thin) and measured actuator pressure (green thick) during a ramp in the control signal. Estimated parameters for the second model are $u_{\min }=12.5, u_{\max }=94.5$.

\subsection{Complete static model}

Combining (3) and (4), gives the complete model for the wastegate position as a function of duty cycle and the two pressures fed to the pressure blender solenoid. Figure 7 shows a validation of the model where it is seen that the model gives a good description of the measured position.

\subsection{Wastegate actuator dynamics}

Step responses in wastegate duty cycle show that there are overshoots both in actuator pressure, Figure 8, and wastegate position, Figure 9. The overshoot in pressure is expected and is sufficiently well described by the static model. This is due to the following. An increase in wastegate duty cycle lowers the actuator pressure, which closes the wastegate. This gives more air flow through the turbine and increases the energy to the compressor. The pressure after the compressor thus increases and since it is connected to the pressure blender solenoid it thereby increases the actuator pressure once again.

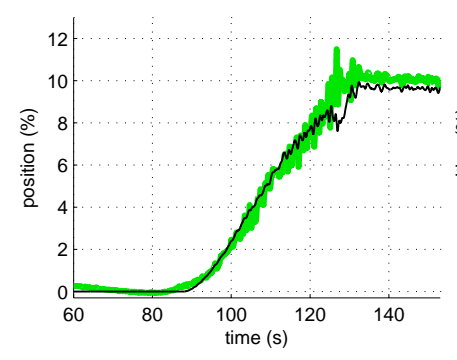

(a) 2500rpm

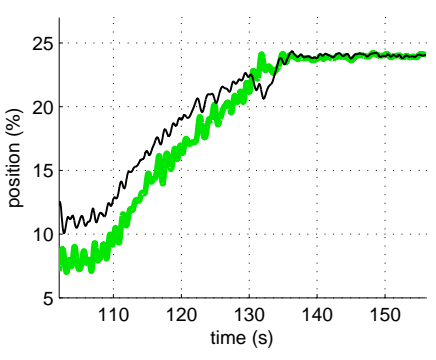

(b) 4000rpm
Fig. 7. Plots for the static model from duty cycle to wastegate position (black thin) and the measured position (green thick). As a result of the pressure model being a little less accurate for the higher engine speeds, so is also the combined model.

The large position overshoots, seen in Figure 9, are not fully explained by the static models. These overshoots have an impact on the transient response which motivates an introduction of dynamics in the wastegate position. This is done by observing that the system in Figure 2 is similar to a mass-spring-damper system, which is a second order system. It turns out that the large position overshoot seen in the measurements can not be described by the regular mass-spring-damper model (5), without adding a zero to the transfer function.

$$
H(s)=\frac{1}{T^{2} s+2 \zeta T s+1}
$$

Adding the term $\beta T s$ to the numerator and setting the damping coefficient to 1 results in the dynamic model

$$
H_{x_{w g}}(s)=\frac{\beta T s+1}{(T s+1)^{2}}
$$

with a double pole in $s=-1 / T$ and a zero in $s=$ $-1 /(\beta T), \beta>1$. An interpretation of the term $\beta T s$ is that the position dynamics is dependent on both the pressure and the pressure derivative. The parameters $\beta$ and $T$ have been tuned manually to match the overshoot in the measurements. Comparisons between the measured position and the static and dynamic models, for steps in wastegate duty cycle, are shown in Figure 9, and it is seen that the model gives a good description of the system behavior.
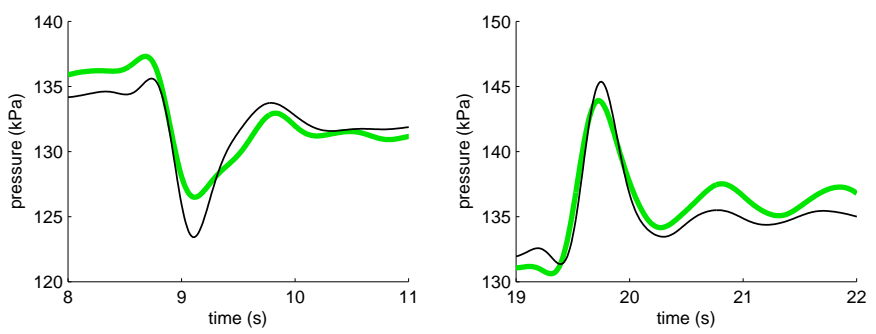

Fig. 8. Measured wastegate pressure (green thick) and calculated wastegate pressure (black thin) with the static model during two steps in wastegate duty cycle at $4000 \mathrm{rpm}$. The pressure overshoot during steps in duty cycle is described satisfactorily by the static model. 

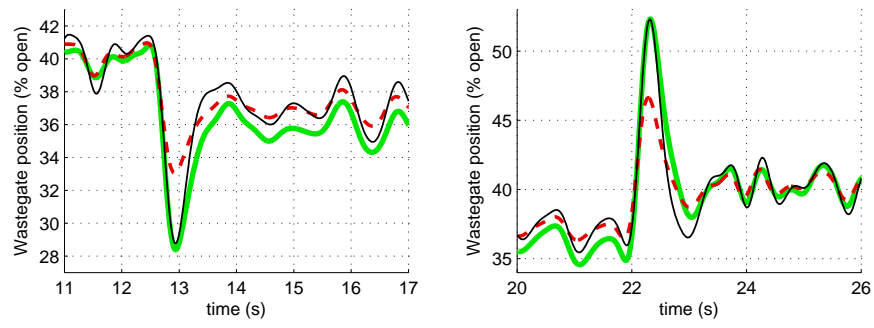

Fig. 9. Measured wastegate position for step responses in duty cycle (green thick) at $4500 \mathrm{rpm}$. With the static model (red dashed) the overshoot in wastegate position is not accurately described by the model. Adding the dynamics (6) to the wastegate position (black thin) improves the model.

\subsection{Full MVEM with Wastegate Model}

To evaluate the developed model and use it for controller tuning the actuator model was implemented in the available MVEM. To be useful when evaluating the controller tuning method the model needs to capture the wastegate duty cycle response on an engine. Figure 10 compares the boost pressure for two step responses in $u_{w g}$ measured in engine test cell with simulations made with the extended MVEM.

When first comparing the measured and simulated values there is a small bias error in pressure. In Figure 10 the bias error has been removed (the maximum offset was $4 \mathrm{kPa}$ ). This is done to be able to better compare the pressure transients which is important for control. This bias error will not affect the control design and tuning, presented in section 3 , but will be handled by the feedforward.

The developed model, consisting of three simple submodels, captures the dynamic behavior of the wastegate actuator. More importantly, together with the MVEM it captures the boost pressure response, including the overshoot, for changes in wastegate duty cycle. A good agreement in the dynamic response between the simulation environment and the engine improves the chances that a design based on the model will work in practice. In the next section the model is used in the development of a controller tuning method.

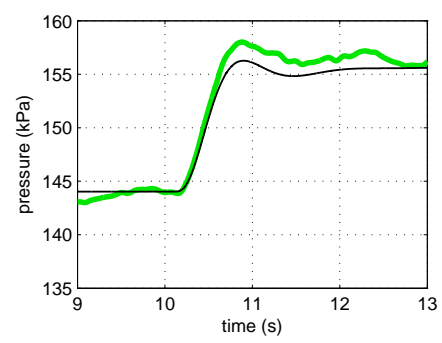

(a) 3000rpm

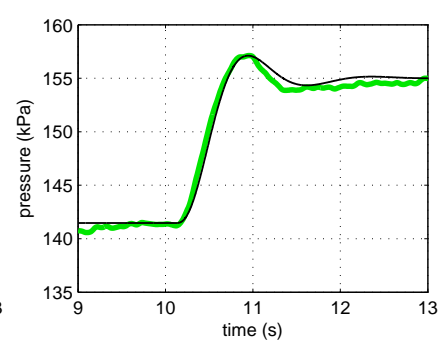

(b) 4500rpm
Fig. 10. A comparison between measured (green thick) and simulated (black thin) boost pressure during a step in wastegate duty cycle. For both engine speeds the simulated pressure behavior is similar to the measured step.

\section{BOOST PRESSURE CONTROLLER}

The controller structure studied in this paper is in industrial use today and consists of a static feedforward and a gain scheduled PID controller, see Figure 11. The feedforward gives the desired boost pressure at stationary conditions. It is determined by running the engine at stationary conditions and recording the duty cycle $u_{w g}$ needed for desired boost pressures. The task of the PID controller is to shape the dynamic response of the system while minimizing the response time during steps in desired boost pressure and eliminating stationary error. This should also be achieved without introducing oscillations. The focus of the following sections is to present and evaluate a systematic method for tuning the PID controller.

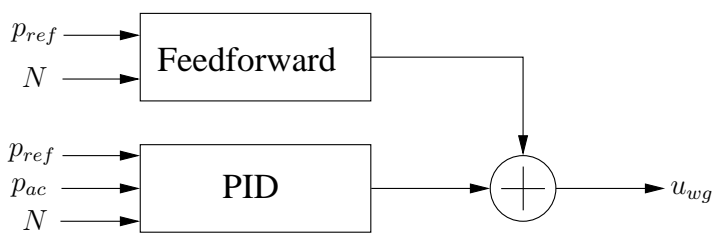

Fig. 11. The controller structure for the boost pressure controller. The feedforward is a static map from desired boost pressure and engine speed to $u_{w g}$. The PID controller parameters depend on engine speed.

\subsection{PID tuning method}

From industrial perspective it is desirable for a tuning method to be simple, fast and easy to automate. To tune the PID controller some experiments for gathering process knowledge is needed. The complete MVEM together with the wastegate actuator model developed in the previous section is a nonlinear model with 15 states. Using this model as the starting point for tuning the PID controller, by linearizing and deriving transfer functions between $u_{w g}$ and $p_{a c}$, would be cumbersome and a simpler model is searched for.

Experimental results indicate that at least a second order system is needed to describe the system behavior for steps in input signal. Several simulations with the MVEM and wastegate model have been performed for different speed and load conditions showing that a second order behavior seems to be sufficient for capturing the important dynamics. For this reason step responses in $u_{w g}$ are suggested for model identification experiments. The behavior of the system changes significantly with engine speed and thus the step responses are done for several engine speeds in the range of interest, resulting in the process model in (7). Plots for two engine speeds measured in a test vehicle are shown in Figure 12.

$$
G(s)=\frac{K(N)}{T^{2}(N) s^{2}+2 T(N) \zeta(N) s+1}-\zeta \leq 1
$$

When identifying the process model the zero level should be set to the boost pressure before the step. Based on the measured step responses with the adjusted zero level, the parameters in the process model can be identified one at 


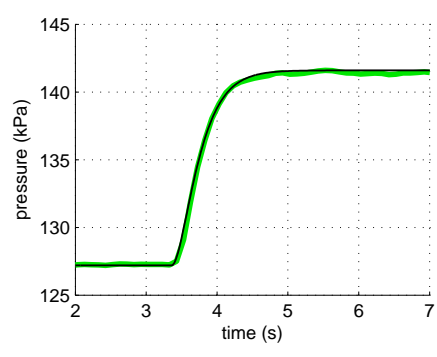

(a) 2500rpm

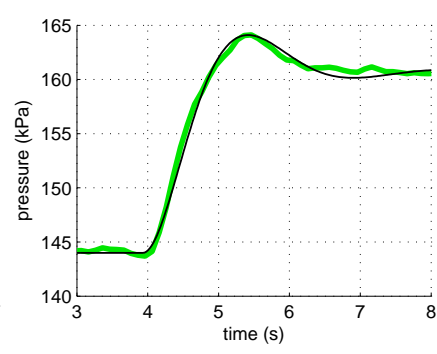

(b) $5000 \mathrm{rpm}$
Fig. 12. Measured boost pressure response in test car to steps in $u_{w g}$ (green thick) together with the adapted process model (black thin) for two different engine speeds. The adapted model shows very good fit to measured data. For 5000rpm the pressure peak is slightly sharper compared to the adapted model, but the difference is very small.

a time with the algorithm below, alternatively an LSQ problem over all parameters can be solved.

(1) $K$ is given by the static gain: $K=\frac{\Delta p_{\text {boost }}}{\Delta w g_{d c}}$

(2) $\zeta$ is a function of the pressure overshoot: $\zeta=f\left(\frac{p_{\text {overshoot }}}{\Delta p_{\text {boost }}}\right)$

(3) $T$ only scales the step response in time and is chosen to best fit the measured step response.

Figure 12 shows a measured step response and the step response for the adapted process model for two engine speeds. The second order model, with different parameters for different engine speeds, gives a good description of the pressure behavior.

The suggested parameter tuning is based on the IMCframework for controller design or Q-parametrization (Garcia and Morari, 1982). Consider the controller structure in Figure 13. The idea is to use the process model to predict the output and only use the new information in the feedback loop. If $G(s)=G_{0}(s)$ the feedback term is zero and the transfer function from reference to output becomes $Y(s)=G(s) Q(s) R(s)$. This means that $Q(s)$ can be used to design the transfer function from $R(s)$ to $Y(s)$ by choosing $Q(s)=G_{d}(s) G^{-1}(s)$ where $G_{d}$ is the desired closed loop transfer function. The IMC structure could be implemented as it is, but can also be transformed into the standard feedback controller with the equation $F(s)=Q(s)(1-G(s) Q(s))^{-1}$.

In general the controller $F(s)$ is not a PID controller, but for many simple process models it is (Rivera et al., 1986). In this case when $G(s)$ is a second order system, and with the choice $G_{d}(s)=1 /(\lambda s+1)$ a PID controller is the result. This choice of $G_{d}(s)$ as a first order system is motivated by the desire to suppress disturbances without introducing

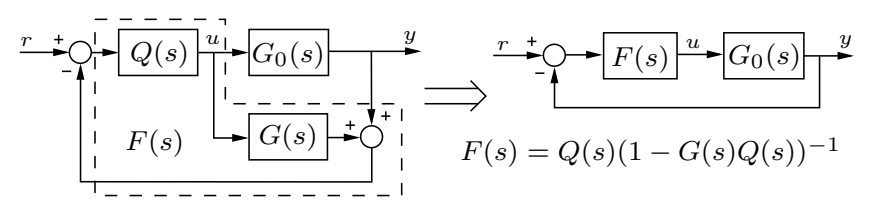

Fig. 13. The standard IMC controller structure and how it can be interpreted as a standard feedback controller. oscillations. The parameter $\lambda$ is a tuning parameter that can be interpreted as the time constant for how fast the controller will react to a control error. Deriving $F(s)$ for the suggested choice of $Q(s)$ gives the ideal PID controller and parameters in $(8)$.

$$
\begin{aligned}
& F(s)=\frac{T^{2} s^{2}+2 \zeta T s+1}{\lambda K s} \\
& K_{p}=\frac{2 T \zeta}{\lambda K} \quad K_{i}=\frac{1}{\lambda K} \quad K_{d}=\frac{T^{2}}{\lambda K}
\end{aligned}
$$

Since the parameters in the second order model are engine speed dependent then also the PID parameters will depend on the engine speed, in the equations above this dependence has been omitted. The choice of the tuning parameter $\lambda$ effects the speed of the controller and will be discussed in section 4 .

\subsection{PID implementation aspects}

A direct implementation of the ideal PID controller, with an unfiltered derivative, is not appropriate due to high frequency measurement noise. The D part of the controller has been filtered with a low-pass filter with a cut off frequency of $20 \mathrm{rad} / \mathrm{s}$.

The low pass filtering of the derivative introduce another problem if steps in reference signal occur. If the derivative act on the control error, $e=r-y$, this results in large transients for sudden changes in reference value. For an unfiltered signal this would only be one sample but when the derivative is filtered it can sustain for several samples. One solution described in Åström and Hägglund (2006) is to let the derivative act on $e_{d}=\beta r-y$ where $\beta$ is chosen between 0 and 1 . In this controller $\beta=0$ is chosen because the derivatives main task is to decelerate the pressure increase after a step in desired boost pressure, when the reference value is reached. For slower and smother changes in boost pressure reference, where a derivative acting on the $e=r-y$ would be preferred, the derivative action is fairly small.

Having integrator engaged when the control signal saturates will cause undesirably large overshoots due to windup. Therefore conditional integration is used to prevent integrator wind-up.

\section{CONTROLLER TUNING AND RESULTS}

Evaluation of the controller and the tuning method is first performed on the complete MVEM with the actuator model developed in Section 2. If the controller performs well in simulation, and the engine model used is accurate, the chance of failure on the engine is small. When the tuning method is proved to work in simulation, it is tested and evaluated on an engine. The response in boost pressure to a step in reference value should be as fast as possible with a small overshoot (around $5 \mathrm{kPa}$ ) and no oscillations. The small overshoot is desired because you do not want a shortage of power but rather a small excess.

The tuning parameter $\lambda$ should be chosen so that the transient behavior described above is achieved. If a too small value for $\lambda$ is used, the controller will be too 
aggressive, and introduce oscillations during transients. With too large value for $\lambda$, disturbances will not be suppressed fast enough and the transient response will be slow. A value of around $\lambda=2$ has proved to be a good starting point for calibration. Engine test cell experiments have shown that engines with a comparatively bigger turbos, and thus slower and smoother response, can tolerate a smaller value of $\lambda$. This can also be needed to achieve the desired closed loop response. Furthermore, a system with fast step response and larger overshoots need larger $\lambda$-values.

\subsection{Controller performance in simulation with the MVEM}

In the simulation evaluation of the control design the steps for the open system, that are utilized in the tuning procedure, were performed on the complete MVEM. Based on these the controller parameters were determined and step responses in desired boost pressure were performed with the boost pressure controller acting on the complete MVEM. Figure 14 shows such step responses for two different engine speeds. The proposed controller gives a smooth pressure transient with an overshoot close to the desired $5 \mathrm{kPa}$. With an accurate model for the engine and especially the boost pressure behavior, this is a good indication that the tuning method will work on the engine.

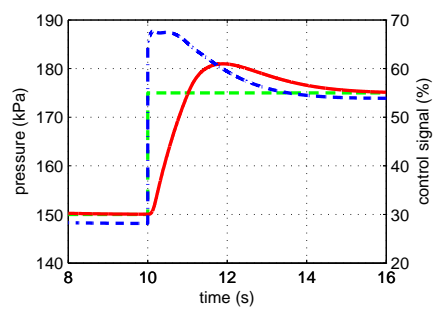

(a) $2500 \mathrm{rpm}$

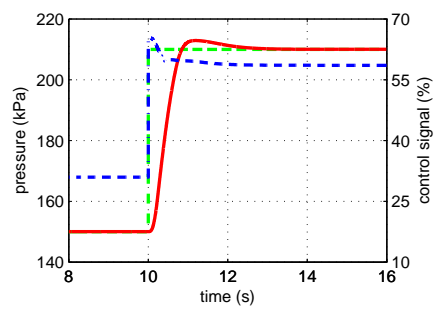

(b) $5000 \mathrm{rpm}$
Fig. 14. Simulated pressure step responses (red solid) and control signal (blue dash-dot) with a step in reference pressure (green dashed). For the two engine speeds the overshoot is, $7 \mathrm{kPa}$ and $3 \mathrm{kPa}$ respectively, which is not far from the desired overshoot of $5 \mathrm{kPa}$.

\subsection{Controller performance in test vehicle}

In the next step the controller is evaluated in a test vehicle and these were done in a vehicle dynamometer. The step responses used for parameter identification have already been presented in Figure 12. Figures 15 and 16 show responses for the closed loop system for different engine speeds and step sizes. Both figures show that the controller successfully achieves the desired performance, i.e. a fast transient response with a small overshoot in boost pressure, not exceeding $5 k P a$, without any significant oscillations.

Even though this paper focuses on the feedback loop it must be noted that the feedforward loop has a profound effect on the performance. Figure 17 illustrates a potential problem if the feedforward is poorly calibrated. In this example the step response is slower and it takes longer time for the controller to converge to the desired set

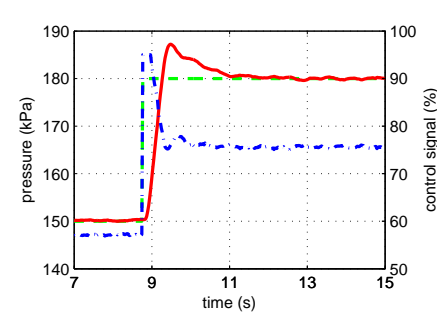

(a) Reference step 150-180 kPa

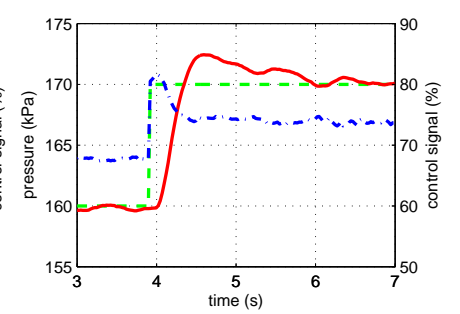

(b) Reference step 170-180 kPa
Fig. 15. Boost pressure step responses for $2500 \mathrm{rpm}$ measured in test car. The overshoot is close to $5 \mathrm{kPa}$ for the larger step response and around $3 \mathrm{kPa}$ for the smaller. There are no significant oscillations present, the small tendency seen in (b) is too small to be felt by the driver.

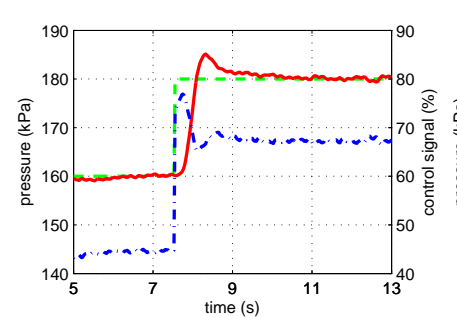

(a) Reference step 160-180 $\mathrm{kPa}$

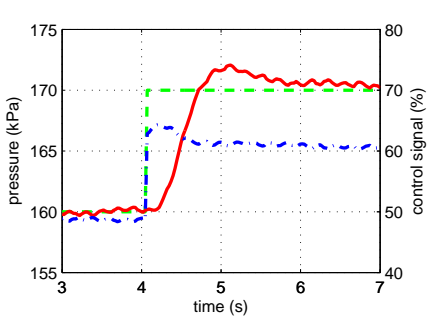

(b) Reference step 170-180 $\mathrm{kPa}$
Fig. 16. Boost pressure step responses for $4500 \mathrm{rpm}$ measured in test car. As for $2500 \mathrm{rpm}$ the overshoot is about $5 \mathrm{kPa}$ for the larger step response and around $3 k P a$ for the smaller.

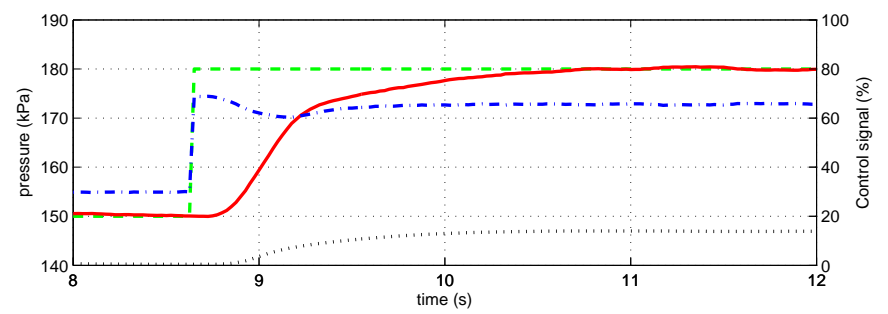

Fig. 17. Boost pressure step response measured in test car that illustrates the importance of accurate feedforward calibration. In this example there is a $13 \%$ error in the feedforward for $180 k P a$ reference pressure. The error is suppressed by the integrator part of the PID controller but the desired shape of the step response is not achieved. The same signals are used as in previous figures with the addition of the integrator in the controller (black dotted).

point. The converse, with a too big overshoot can also occur. The integrator part of the controller removes the stationary error but slow convergence or big overshoots in the transient response are undesirable.

\subsection{Controller performance for a slower system}

An engine setup with a much larger turbo fitted on the engine is used to further investigate the applicability of the control design. Experiments from that engine configuration on a dynamometer, are shown in Figure 18. With the bigger turbo this system has a much slower step response 


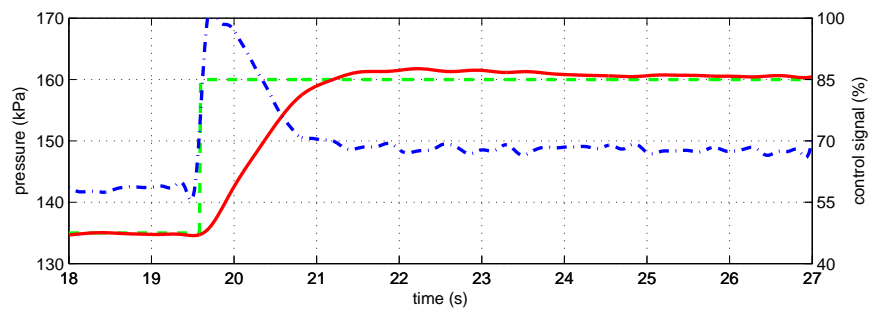

Fig. 18. Boost pressure step response measured in an engine test cell with a bigger turbo fitted to the same engine, hence a slower system. It is seen that the control design gives the desired behavior with a fast control response that is balanced against a small overshoot.

compared to the previous ones, and the same closed loop performance can therefore not be achieved. However as can be seen in the figure the qualitative behavior of the closed loop system is still achieved, i.e. with as fast response as possible balanced against a small overshoot. In this case a smaller $\lambda$-value is used, as was indicated in the discussion of the controller tuning. These results further strengthens the conclusion that the proposed control design successfully achieves the desired behavior.

\section{CONCLUSIONS}

Wastegate modeling and boost pressure control in a TCSI engine has been studied. A new and simple wastegate actuator model has been developed that captures the main behavior of the actuator. The actuator model is composed of three simple submodels: the actuator pressure, the static position, and an additional position dynamics. The dynamics of the actuator turns out to be important for the transient boost pressure behavior. In particular there is an overshoot in the boost pressure for step changes in the actuator control input that is caused by the actuator characteristics.

The actuator model is inserted in an existing MVEM, that describes the gas flows of the engine, and the complete model is used to predict the transient behavior of the wastegate and boost pressure. These transient responses are studied for different conditions and give insight into the properties of the system and thus valuable input to the boost pressure controller. With the aid of the complete MVEM a boost pressure controller, consisting of a feedforward and a gain scheduled PID controller, is developed together with a tuning method based on the IMC framework. Evaluations are performed both on the complete MVEM and on engines where the proposed controller and tuning method is shown to achieve the desired transient behavior in boost pressure. The applicability of the control design and tuning method is experimentally demonstrated, both on an engine in a vehicle and in a test cell where a larger turbo is fitted to the engine. In the latter evaluation the design method is put to test on a slower system and still achieves the desired behavior.

\section{REFERENCES}

Andersson, P. (2005). Air Charge Estimation in Turbocharged Spark Ignition Engines. Ph.D. thesis, Linköpings Universitet.
Emmenthal, K.D., Hagermann, G., and Hucho, W.H. (1979). Turbocharging small displacement spark ignited engines for improved fuel economy. SAE Automotive Engineering Congress Exposition. Detroit, Michigan, USA.

Eriksson, L. (2007). Modeling and control of turbocharged SI and DI engines. Oil $\&$ Gas Science and Technology Rev. IFP, 62(4), 523-538.

Eriksson, L., Frei, S., Onder, C., and Guzzella, L. (2002a). Control and optimization of turbo charged spark ignited engines. IFAC World Congress. Barcelona, Spain.

Eriksson, L., Nielsen, L., Brugård, J., Bergström, J., Pettersson, F., and Andersson, P. (2002b). Modeling of a turbocharged SI engine. Annual Reviews in Control, 26(1), 129-137.

Galindo, J., Climent, H., Guardiola, C., and Doménech, J. (2009). Modeling the Vacuum Circuit of a Pneumatic Valve System. Journal of Dynamic Systems, Measurement and Control, 131.

Garcia, C.E. and Morari, M. (1982). Internal model control. 1. a unifying review and some new results. Ind. Eng. Chem. Process. Des. Dev., 21, 308-323.

Guzzella, L., Wenger, U., and Martin, R. (2000). IC-engine Downsizing and Pressure-Wave Supercharging for Fuel Economy. SAE Technical Paper 2000-01-1019.

Kranik, A.Y., Buckland, J.H., and Freudenberg, J.S. (2005). Electronic throttle and wastegate control for turbocharged gasoline engines. Proceedings of the American Control Conference, 7, 4434-4439. ISSN 0743-1619.

Moraal, P., Kolmanovsky, I., and van Nieuwstadt, M.J. (1999). Modeling and Identification of a Current to Vacuum Transducer and VNT actuator. Proceedings of the 1999 IEEE/ASME International Conference on Advanced Intelligent Mechatronics. Atlanta, USA.

Moulin, P., Chauvin, J., and Youssef, B. (2008). Modelling and Control of the Air System of a Turbocharged Gasoline Engine. In Proceedings of the 17th IFAC World Congress, 8487-8494.

Müller, M. (2008). Estimation and Control of Turbocharged Engines. SAE Technical Paper Series, 2008 World Congress. Detroit, Michigan.

Petitjean, D., Bernardini, L., Middlemass, C., Shahed, S.M., and Hurley, R.G. (2004). Advanced gasoline engine turbocharging technology for fuel economy improvements. SAE Technical Paper 2004-01-0988.

Rivera, D.E., Morari, M., and Skogestad, S. (1986). Internal model control. 4. pid controller design. Ind. Eng. Chem. Process. Des. Dev., 25, 252-265.

Soltic, P. (2000). Part-Load Optimized SI Engine Systems. Ph.D. thesis, Swiss Federal Institute of Technology, Zürich.

Åström, K.J. and Hägglund, T. (2006). Advanced PID Control. ISA-The Instrumentation, Systems, and $\mathrm{Au}-$ tomation Society. ISBN 1-55617-942-1.

Wakeman, R.J. and Wright, D.O. (1986). Closed Loop Turbocharger Control with Transient Wastegate Functions. SAE Technical Paper 86048\%.

Watson, N. and Janota, M. (1982). Turbocharging the Internal Combustion Engine. The Macmillan Press ltd. ISBN 0-333-24290-4. 